\section{ELECTROCHEMICAL RESPONSE OF DIAMOND FILMS GROWN ON RETICULATED VITREOUS CARBON AT DIFFERENT GRAPHITIZATION INDEX}

\author{
Alessandra V. Diniz ${ }^{1,2}$, Vladimir J. Trava-Airoldi ${ }^{1}$ \\ Neidenêi G. Ferreira* ${ }^{1}$
}

1. Instituto Nacional de Pesquisas Espaciais- INPE, 12.245-970, São José dos Campos, Brazil;

2. Instituto Tecnológico de Aeronáutica- ITA, 12.228-900, São José dos Campos, Brazil; *neidenei@las.inpe.br

Several materials have been used as substrates for diamond electrodes: silicon, metals, alloys and carbonaceous materials. The $\mathrm{sp}^{2}$-bonded carbon materials can present good film-substrate adhesion and minimize the resistance of the ohmic contacts, which are necessary while making electrochemical measurements. Graphite [1], glassy carbon (or monolithic vitreous carbon) [2] and carbon fibers [3] have been the principal materials used for this application. Reticulated vitreous carbon (RVC) is a three-dimensional carbonaceous material with large superficial area, commonly used as electrode. In this work, RVC is used as substrates in diamond depositions and it is related their heat treatment temperature (HTT), which determines their graphitization index, with diamond/RVC electrodes behaviors.

Furfuryl resin impregnated in polyurethane foam was carbonized and exposed at temperature of 1000-2300 K. After pre-treatment, boron doped-diamond films were grown on these samples in a HFCVD reactor. The parameters used were: $6.6 \mathrm{kPa}, 1070 \mathrm{~K}$ at substrate, 100 sccm for total gas flux and $1.0 \%$ vol. $\mathrm{CH}_{4}$ in $\mathrm{H}_{2}$. Boron was obtained from $\mathrm{H}_{2}$ source containing $\mathrm{B}_{2} \mathrm{O}_{3}$ dissolved in methanol. SEM images were obtained from Jeol equipment JSM-5310. CV measurements were carried out using a potentiostat Omnimetra Instrumentos PG 3901 and three-electrodes (work, $\mathrm{Ag} / \mathrm{AgCl}$ and $\mathrm{Pt}$ ) in a singlecompartment electrochemical cell.

The obtained films are showed in Fig.1 and 2. It is possible to note the film covering completely the substrate, including deeper planes (Fig.1). The film is polycrystalline, with uniform texture presenting preferentially (111) and (100) type planes (Fig. 2). In addition, the grains have symmetrical and smooth faces. Figure 3 shows cyclic voltammograms of diamond electrodes on RVC, produced at two different temperatures, in $1 \mathrm{mmol} / \mathrm{L} \mathrm{K}_{3} \mathrm{Fe}(\mathrm{CN})_{6}$ solution. The 1300 $\mathrm{K}$ HTT electrode presented the peak separation larger than electrode treated at higher HTT. Considering also other results, it is possible to conclude that 2300 HTT electrode presents more reversible behavior. This fact can be related to the substrate properties influenced by HTT, mainly electrical resistivity, once diamond films have obtained at the same experimental conditions. Previously, the RVC electrical resistivity measurements presented different values, as it was expected.

In summary, the results have shown a strong relation among RVC HTT and electrochemical responses of diamond films grown on these substrates.

[1] C.H. Goeting et al, Journal of Electroanalytical Chemistry, 442 (1998) 207.

[2] R. Ramesham, R.F. Askew, M.F. Rose, B.H. Loo, Journal of Electrochemical Society, 140 (1993) 3018.

[3] N.G. Ferreira, LL.G. Silva, E.J. Corat, Diamond and Related Materials, 11 (2002) 675.

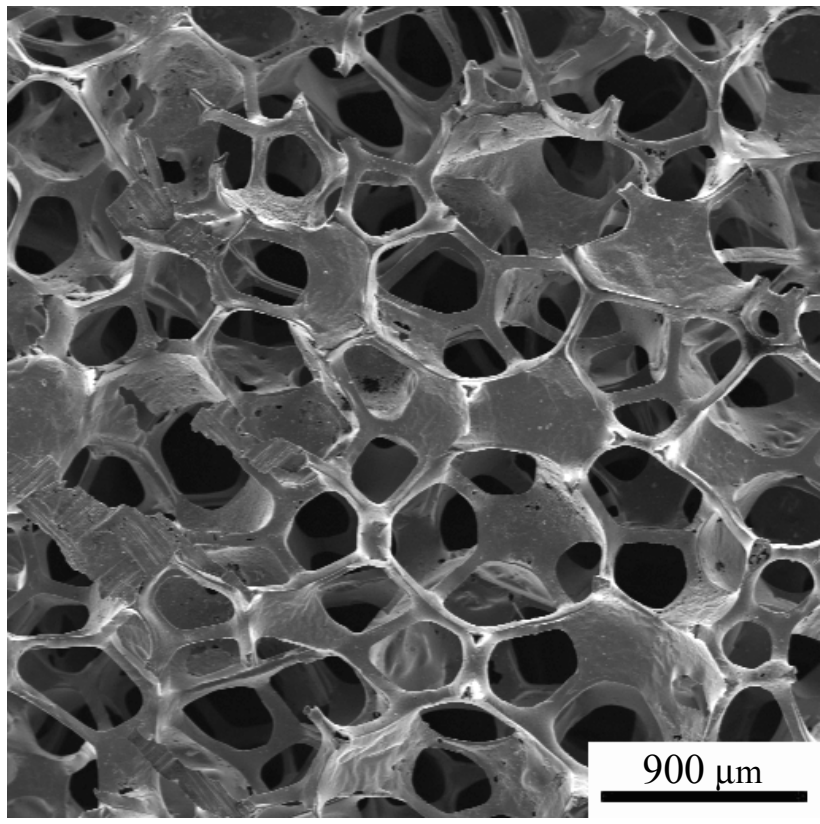

Figure 1. SEM image (35x) of doped-diamond on RVC produced at $1300 \mathrm{~K}$.

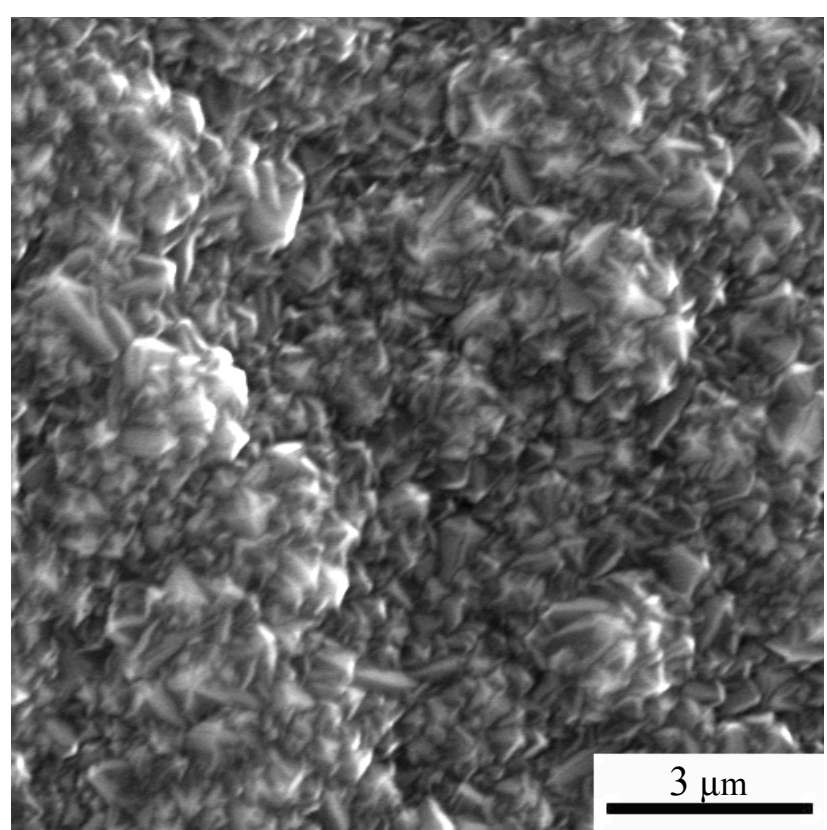

Figure 2. SEM image (10Kx) of doped-diamond on RVC produced at $1300 \mathrm{~K}$.

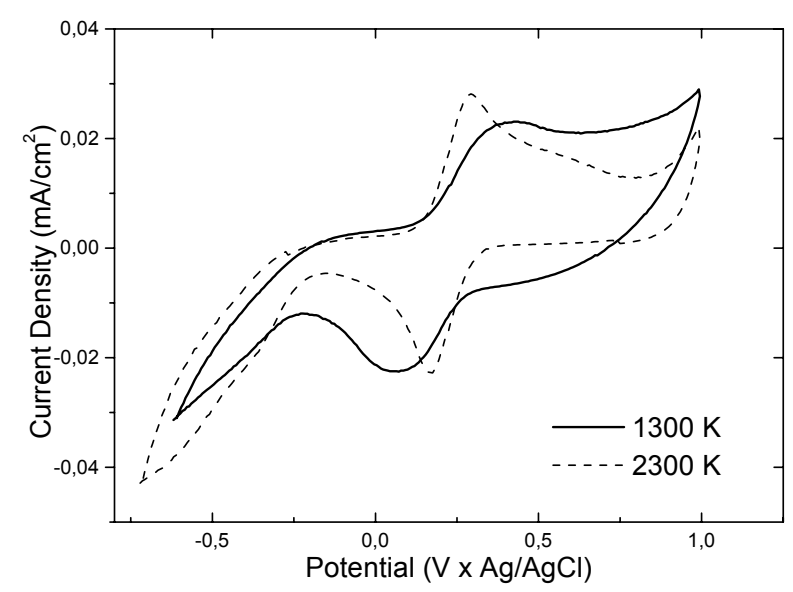

Figure 3. Cyclic voltammetric behavior at $5 \mathrm{mV} / \mathrm{s}$ in 0.1 mol/L $\mathrm{KCl}$ solution containing $1 \mathrm{mmol} / \mathrm{L} \mathrm{K}_{3} \mathrm{Fe}(\mathrm{CN})_{6}$ of boron-doped diamond grown on RVC produced at 1300 an $2300 \mathrm{~K} \mathrm{HTT}$. 